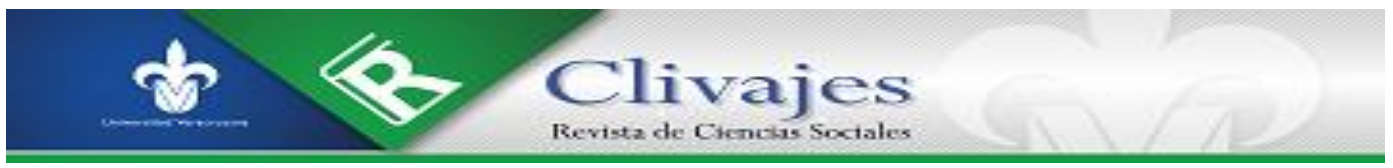

Daniel Bello López

VALORES Y FORMAS DE ORGANIZACIÓN COMUNITARIA

PARA LA GESTIÓN TERRITORIAL EN EL TOTONACAPAN VERACRUZANO

Clivajes. Revista de Ciencias Sociales. Año V, número 10, julio diciembre 2018, pp. 95-122.

http:// clivajes.uv.mx/index.php/Clivajes/article/view/2552/4435

Instituto de Investigaciones Histórico-Sociales, Universidad Veracruzana

C livajes. Revista de Ciencias Sociales/ISSN: 2395-9495/IIH-S, UV/Xalapa, Veracruz, México.

Recibido: $14-02-2018$

Aceptado: 20/03/2018

Dictaminado: 19/09/2018

Publicación: 03/12/2018

Clivajes. Revista de Ciencias Sociales (ISSN: 2395-9495), Año V, Núm. 10, julio-diciembre, 2018 


\title{
VALORES Y FORMAS DE ORGANIZACIÓN COMUNITARIA \\ PARA LA GESTIÓN TERRITORIAL EN EL TOTONACAPAN VERACRUZANO
}

\author{
Daniel Bello López
}

\section{Resumen}

Este trabajo da cuenta de la etapa exploratoria del proyecto "Formación ciudadana para la interculturalidad y la ciudadanía diferenciada. El acompañamiento de promotores de los derechos indígenas y la democracia activa solidaria"; que se propone contrastar los valores de la ciudadanía liberal, con los del ejercicio de ciudadanía en el ámbito comunitario y la democracia directa que comunidades totonacas practican en los municipios de Zozocolco y Espinal, Veracruz.

El texto pretende empezar a responder a una de las preguntas de investigación del proyecto: ¿Qué tipo de valores y principios deben ser incluidos, como contenidos, en una formación ciudadana que contribuya a la ciudadanía diferenciada? Se reflexiona sobre las implicaciones del concepto de valores, haciendo énfasis en el de confianza. Se hace un breve recuento de los valores practicados por los totonacos, según algunos autores, para luego, analizar la forma en que los valores orientan la acción social de los individuos durante los procesos de organización comunitaria.

Palabras clave: Valores, Confianza, Solidaridad, Participación, Organización comunitaria

\section{INTRODUCCIÓN}

El texto se construye a partir de ejercicio introspectivo e investigación diagnóstica, mediante talleres de reflexión y etnografía interpretativa, en mayor medida, y con la comunidad totonaca de Buenavista, municipio de Espinal, Veracruz. En esta comunidad, se emprende un proyecto de intervención y actividades para construir situaciones de aprendizaje, como parte de un proceso de educación, no reglada, para la formación ciudadana, que se han reflejado en reuniones, foros, talleres e información obtenida a través de entrevistas. La información se sistematiza para captar el significado de aquellos valores practicados por los totonacos que se pretende incorporar como "contenidos significativos" en un curso-taller para su multiplicación, la revitalización de las instituciones comunitarias y la participación social para una buena vida.

\footnotetext{
* Doctor en Historia y Estudios Regionales por el Instituto de Investigaciones Histórico-Sociales y Docente de Tiempo Completo en la Universidad Veracruzana Intercultural, sede Totonacapan, Veracruz, México.
} 


\section{VALORES, SU INTENCIÓN Y SIGNIFICADO}

Es importante emprender un acercamiento conceptual a los valores para no dar por sentada su existencia como "algo trascendental”. Los valores deben ser practicados y promovidos, porque reproducen una identidad y funcionan como articuladores del orden, guías de la acción, resultado de una condicionante cultural.

Para Max Weber, la acción social tolerada u omitida se orienta por la acción de otros y puede estar orientada, con arreglo a fines o valores, por lo afectivo y por la tradición. Según Weber (1984), en la acción racional con arreglo a valores, el individuo actúa por "mandato": al creer en el valor, el actor se ve obligado a actuar conforme éste lo recomienda. Desde la perspectiva sociológica de Talcott Parsons (1991), según Víctor M. Durand Ponte (2004), los valores también orientan la acción de los agentes o actores, pero plantea, además, que actúan como "elemento articulador del orden social” (p. 88); para ello, los valores deben ser interiorizados mediante un proceso de socialización.

De acuerdo con Durand (2004), para Parsons los valores tenían validez universal; en cambio, para sus críticos: "b) los valores pueden ser aceptados pragmáticamente antes que normativamente” (p. 89). Retomamos aquí los planteamientos de Durand sobre la validez de los valores con respecto a la sociedad y cultura que los procesa y acepta, porque los define como producto de la reflexividad del individuo y no como resultado de "algo trascendental". Aun cuando emplea su operacionalización para caracterizar la cultura política, la definición de valores resulta importante para nuestro caso, en tanto se sitúan en el plano de la construcción racional, condicionada por un contexto cultural que propone una forma de ser, actuar y deber ser a través del consenso:

Desde nuestra perspectiva, los valores son normas de carácter general que intervienen en el cálculo de la acción de los individuos. Los valores no tiene validez fuera de las sociedades en donde funcionan como reglas o partes de éstas; por lo tanto, no tienen un sustento trascendental, no son universales per se. Los valores, como las reglas, surgen de la reflexibilidad de los individuos, los cuales, como ya mencionamos, siempre monitorean su acción y son expertos en su manejo. Los valores constituyen, dentro de un régimen político, el consenso no discutible, una especie de acuerdo general de lo que debe ser el sistema político (Durand, 2004:90).

María Bertely (2007), quien ha explicitado los valores de los pueblos indígenas de los Altos de Chiapas, para luego sistematizarlos como contenido de la educación ciudadana para la democracia activa y solidaria, se refiere a ellos como: "mecanismos de control de la vida comunitaria que les permitían resistirse, contrariar la sumisión y encarnar en la vida práctica una democracia activa y solidaria” (p. 55). 
En suma, los valores tienen validez normativa, pero relativa, y su infracción se sanciona moralmente; en ciertas circunstancias sirven como mecanismos de control social y orientan la acción, ya sea para resistir, al contrariar lo establecido, o para articular la vida social; son aceptados por convención racional para alcanzar el consenso a través del diálogo y debate público. Los valores son resultado de la reflexión racional, del diálogo; pueden llevarse a la práctica, realizarse a través de acciones ejecutadas públicamente, y se asumen por convención, no por resultado de algo trascendental (Salazar y Woldenberg, 2008).

Un trabajo parecido al de Durand sobre valores y cultura política para el caso de Veracruz, es el de Leopoldo Alafita (2012), quien explora la relación entre tolerancia y democracia para la convivencia social. ${ }^{1}$ Coincidimos con su preocupación por la otredad y la percepción diferenciada que, a su juicio, tienen que ver con los "distintos orígenes" de los individuos en interacción, condicionados por las diferencias culturales de las cuales son portadores (pp. 104-105).

En su análisis de la cultura política, Durand (2004) asigna suma importancia a las actitudes que asume el ser humano, las cuales asocia con las creencias que permiten al individuo percibir, interpretar y establecer tendencias en su actuación. Para este autor, las “actitudes básicas" del ser humano para alcanzar consensos y actuar racionalmente son la tolerancia y la confianza; esta última actitud básica puede construirse y referirse a lo interpersonal, y a las instituciones. Llama la atención que en algunas ocasiones el mismo Durand se refiera a la tolerancia como "otro de los valores fundamentales de la cultura democrática” (p. 91).

La confianza permite alcanzar el consenso democrático, acrecentar el capital social. Construida de manera eslabonada, la confianza articula el tejido social y resulta fundamental para el funcionamiento de la sociedad, al integrar al individuo a redes de parentesco, vecinales, e instituciones y organizaciones, mediante el establecimiento de relaciones basadas en la reciprocidad y el comportamiento honrado, y orientadas por valores que favorecen la colaboración; esto constituye y reproduce el capital social, organizativo, al generar relaciones horizontales, de autoayuda, de trabajo voluntario, que construyen un estilo de vida para alcanzar logros, un consenso democrático:

Sin confianza, no existe la participación voluntaria y libre de los ciudadanos para conformar organizaciones que defiendan sus intereses, que articulen sus demandas y que los conviertan en ciudadanos participantes y competentes frente al Estado para lograr la satisfacción de sus intereses. La

\footnotetext{
${ }^{1}$ Sin embargo, en relación con la "cuestión indígena”, sólo analiza la tolerancia como valor para la convivencia entre la población mestiza y la indígena en Veracruz; en correlación con la perspectiva de género, encuentra que las mujeres son quienes muestran mayor rechazo racial hacia las persona indígenas y por militancia partidaria, los del PRI y PAN (Ver cuadros en Alafita, 2012:115-116).
} 
confianza interpersonal, basada en la reciprocidad y en el carácter previsible de la conducta o reacción de los otros, se convierte en el cemento de la organización democrática (Durand, 2004:94).

La confianza en las instituciones "es un lazo que une a los individuos con la sociedad" (Durand, 2004:95). Son dichas instituciones las que, por lo regular, fijan reglas de comportamiento y procedimientos administrativos para el acceso a los recursos. Si las reglas son claras y respetadas, dan certidumbre, por lo que se convierten en referentes y orientadoras de la acción social. Al dar legitimidad a la autoridad, promueven la reciprocidad que cumple expectativas de la gente y encauzan la cooperación voluntaria, así como la participación libre y activa, que redunda en colaboración con las instituciones.

Ahora bien, en tanto nuestro interés no es analizar la cultura política, sino las formas de organización y gestión comunitaria, nos centraremos en la confianza, como valor que dinamiza la participación libre y activa, y que puede incidir en la cooperación voluntaria para la gestión del desarrollo, sin detrimento de la tolerancia: actitud que predispone al entendimiento para la convivencia entre quienes piensan diferente, pues obliga a escuchar puntos de vista diferentes, a buscar el consenso, y coadyuva, además, a la toma de decisiones, de manera democrática y voluntaria, en beneficio de la comunidad.

Una vez caracterizados los valores y definida la confianza como dinamizadora de la participación y la organización social, pasamos a un recuento de lo que se ha escrito sobre valores de los totonacos, para luego contrastarlos en situaciones empíricas, donde pueden ser observados, e interpretar, a la vez, su ejercicio, su práctica, a la luz de algunas conceptualizaciones de diversos autores.

\section{PRESENCIA Y APROPIACIÓN DE VALORES ENTRE LOS TOTONACOS}

Resulta un lugar común decir que todo grupo humano se guía por valores y principios, y también que en tiempos de globalización los valores y principios se ven amenazados, sobre todo, los de las culturas subordinadas, como es el caso de las pertenecientes a pueblos originarios que han estado sometidos a un proceso de aculturación y políticas integracionistas. Para no incurrir en ello, una revisión de lo escrito sobre los totonacos permite explorar su práctica y vigencia.

Según Margarita Urías Hermosillo (1987), a finales del primer lustro de los años 80 del siglo XX, la sierra de Papantla estaba poco permeada de los seudovalores del "hombre de razón”. Se practicaban la confianza mutua y la honradez, el respeto al hombre de edad madura y a la naturaleza. Se mantenía una lealtad a la tradición, que contribuía a la "felicidad colectiva”: cada cual en el pueblo totonaco vivía apegado a los valores que promovían la 
integración de la familia, y se sentía orgulloso de ser totonaco, de su identidad étnica (p.10). Sus conductas individuales y colectivas se regulaban por:

la solidaridad y la felicidad colectivas cuando trascienden el mundo de las necesidades materiales durante las fiestas y rituales donde se expresa el honor de cumplir con las responsabilidades comunitarias, cubriendo los cargos que la tradición les confiere para que la religiosidad continúe garantizando una espiritualidad alejada del poseer y acumular en términos individuales, interés prioritario que da sentido a la sociedad nacional (Urías, 1987: 11).

Sin embargo, Urías también reconoce que, para los totonacos de Chumatlán, Coxquihui y Zozocolco, el progreso sólo produce insatisfacciones, por lo que: "intentan -en muchos casos- superar las limitaciones sociales y personales, condensando los valores universales" (p. 14) al asumir algunos de éstos. Por todo ello, el totonaco vive y se adapta a las relaciones capitalistas que promueven un modo egoísta de vida, donde "ellos se transforman y avanzan en un continuum histórico que garantiza su especificidad” (Urías, 1987:12).

Masferrer Kan (2004) menciona que en el caso de los totonacos, además del faccionalismo político y sectas religiosas, existen diversos factores que un primer momento generan divisionismo - lo cual José Luis Blanco (1987:237-238) asocia con la diversidad que aflora como potencial del conflicto sociopolítico-, pero también contribuyen a la reconfiguración de la organización comunitaria, al apropiarse, los actores, de nuevas formas de organización, lo que pasa por una desestructuración del tejido social, a veces de desmovilización social, al incentivarse la participación comunitaria mediante programas gubernamentales y la pérdida de confianza en sus instituciones de servicio a la comunidad:

En la actualidad este sistema de participación comunitaria está desmovilizado; la migración de los jóvenes les dificultó el cumplimiento y además el gobierno implementó una política de pagar todos los cargos municipales; igualmente, mediante los programas de empleo emergente comenzó a remunerar todos los servicios municipales, desestructurando este sistema en aproximadamente diez años. Ahora sólo se mantiene en ciertas comunidades, y es motivo de orgullo de las mismas mantener estas instituciones sociales. En términos políticos es una forma de reorganización que plantea nuevas formas de configuración de las facciones (Masferrer 2004: 28).

Todo lo anterior puede llevar a la apropiación de valores reinterpretados para reorganizar la regionalidad. La mayoría de los autores consultados aborda dicha cuestión de manera genérica en el Totonacapan; no definen los valores, pero implícitamente hablan de ellos, al describir e interpretar situaciones problemáticas que, para ser enfrentadas, requieren la reinterpretación de valores, y distinguen, asimismo, la emergencia de nuevos valores. Pasemos a revisar esos planteamientos que vislumbran la "regionalidad construida" 
como "identidad envolvente", lo que da pauta a una nueva situación sociopolítica, a diversos tipos de acción colectiva y formas de organización con base en valores "reinterpretados".

\subsection{Pluralismo para la convivencia de la diversidad y la democracia}

Según Ramón Ramírez (2002), en la relación de los totonacos con lo local, regional y global, es posible distinguir tres tipos de lealtades políticas, que se inscriben en el sistema de control, en buena parte mediante el patronazgo y la intermediación, pero que también dan pie a la tolerancia que finca las bases del pluralismo ideológico y la diversidad sociopolítica.

Por un lado, se distingue la lealtad hacia las instituciones y políticas oficiales a través del clientelismo operado por liderazgos tradicionales y burocráticos, vinculados a programas y políticas públicas del Estado, para renovar relaciones de control corporativas; por otro, la lealtad a los patrones, mediante el "patronazgo", caracterizada por promover, entre los grupos, la fidelidad a los intereses del patrón: se expresa como una "red piramidal" cuando éste excluye o apoya, con base en criterios de control político, a sus dependientes económicos, los cuales pueden convertirse en sus seguidores, pero no actúan libremente; por último, la lealtad a la utopía implica el ejercicio de "una nueva política" que demanda una gestión autónoma y democracia regional, que teje redes de solidaridad entre organizaciones de productores con proyectos, incluso rentables, y comités de la sociedad civil: "Los que así piensan, se asumen como totonacos y por la defensa de la dignidad de los totonacos" (Ramírez, 2002:455).

Este sistema de control, afirma el autor, empieza por la disidencia, que surge de la “existencia de una ética local”, basada en valores, "que [los] reorganiza", y éstos son reinterpretados por los lugareños para "captar", reflexionar sobre su realidad comunitaria en relación con lo (municipal) regional y nacional (p. 456). Para Ramírez, la lealtad a la utopía se manifiesta en el plano comunitario o municipal, ligada a lo nacional y global:

en la forma como un totonaco militante y disidente de la política local-comunitaria, con su soledad, con su conciencia y sus iniciativas, se ubica en la política regional y nacional y su noción sobre la humanidad, le amplía su percepción sobre su realidad inmediata: son totonacos que piensan globalmente y así mantienen su lealtad a la utopía (Ramírez, 2002:453).

A decir de Ramírez, las empresas sociales de los totonacos funcionan mediante "mecanismos democráticos" que renuevan la práctica política en las comunidades y municipios, al cuestionar, criticar, el modelo centralista, con base en el consenso, la democracia local y nuevos esquemas innovadores de la organización del trabajo, con 
liderazgos que promueven nuevas relaciones de intermediación para la gestión eficaz ante las instituciones gubernamentales, no sólo como práctica sino como derecho colectivo.

Las luchas de los totonacos van contra el centralismo, el verticalismo y, en la medida que hacen una "reinterpretación de valores" para el diseño de nuevas reglas y formas de organización social autogestiva ante el paternalismo, demandan una gestión autónoma de sus empresas sociales y construir su propio modelo integral de desarrollo sociocultural:

Este tiene varios componentes, comenzando por la defensa de su propio patrimonio cultural y ecológico, como el rescate e incremento de sus propios saberes, su idioma, medicina tradicional, pero aún más, deberá incorporar innovaciones y apropiación de elementos que les permitan afianzar sus proceso democráticos (p. 461).

Lo anterior pasa por el reconocimiento de sus derechos colectivos, como pueblos sujetos de derechos, para manejar su propia política agraria y agrícola, "lograr soberanía sobre su territorio", que es su espacio productivo y vivido cotidianamente.

El proyecto de región totonaca, la "regionalidad construida", es un modelo ideal en construcción que empíricamente se contrasta en asambleas, mediante el discurso de los totonacos sobre y contra "lo que debe ser", para reflexionar sobre su situación e impulsar cambios mediante acuerdos, consensos: "La noción de lo que 'debe ser' la llenan con sus normas, valores, estilos de vida, etcétera, convirtiéndose en un 'modelo ideal' cuya búsqueda se traduce en la lucha cotidiana contra el poder” (Ramírez, 2002: 463).

La nueva regionalidad totonaca, se presenta como una "identidad envolvente" que permite coincidencias, consensos, acuerdos entre familias, grupos, comunidades; se construye como un prototipo de región desde el imaginario de la militancia disidente, que a su vez posibilita: "afianzar o incrementar las relaciones solidarias entre ellos, con la idea de que 'nosotros somos los que estamos aquí y queremos vivir mejor', pero sobre todo, tienen seguridad porque se imaginan cómo lograrlo" (Ramírez, 2002: 464-465).

La identidad envolvente es una síntesis de identidades menores: individuales, familiares y comunitarias, que funcionan como "mecanismos democráticos" para el diseño y construcción de la nueva regionalidad, basada en consensos comunitarios, en la tolerancia, para evitar "actitudes desorganizadoras":

En la práctica permite conciliar las tensiones o divergencias entre la diversidad de identidades o lealtades que a escala individual o de grupos existan, así en la misma organización pueden participar militantes de diferentes partidos, (...) o que participen diferentes religiones. Los de la sierra se sienten tan totonacos como los de la costa (Ramírez, 2002:466). 
A manera de recapitulación sobre lo que se ha escrito en torno a la práctica de valores entre los totonacos, a partir de una relación intercultural realmente existente, que a pesar de su asimetría, de lo desigual, ha dado pie a una influencia mutua de valores entre los portadores de culturas diferentes. Y mediante una apropiación de éstos, las comunidades totonacas, reivindican derechos, construyen una nueva regionalidad, recrean su identidad y alientan la autonomía de sus procesos organizativos y productivos para el control de su territorio, su inserción a mediano plazo en un modelo de desarrollo, que les beneficie y respete en sus derechos colectivos como pueblo.

Lo anterior, es el escenario regional sobre el que diversos autores han reflexionado y supuesto en relación con el desarrollo genérico de los valores ligados a la democracia, las luchas por sus derechos, etc. Pasemos ahora a interpretar los descriptores que hacen observables la práctica de valores entre los totonacos de Buenavista.

\section{APROPIACIÓN DEL TERRITORIO Y TIPOS DE SOLIDARIDAD}

La historia oral registra que a inicios del siglo Xx, cuando la Hacienda Medio Día, ubicada en el municipio de Espinal en el Totonacapan veracruzano, fue vendida a un "gringo", éste desalojó a los peones y arrendatarios con acciones violentas (Muñoz, Vicente y Santiago, 2015). "El gringo" pudo ser J. A. Brown, ${ }^{2}$ quien, en uno de los planos elaborados en 1962 , aparece todavía como colindante del actual Ejido Buenavista, entre la mojonera 3 y la 4, en la parte noreste que actualmente corresponde a las colindancias con el Ejido Santa Catarina y Ciruelo.

Ante este antecedente, cobra sentido la versión sobre la compra de la hacienda por un "gringo" y el posterior desalojo de los peones y pobladores de los alrededores, quienes se refugiaron, a partir de entonces, en el monte de la parte alta de la hacienda, adonde actualmente se ubica el poblado Buenavista, y tomaron posesión, como arrendatarios, ${ }^{3}$ de las tierras montosas en disputa. Esto dio lugar a la fundación de un nuevo asentamiento: el centro de población ejidal Buenavista, por quienes fueran peones acasillados de la Hacienda Medio Día, cuando vivían en un caserío de las inmediaciones del predio Meridiano, cerca del actual Oriente Medio Día, en el actual entronque de la carretera a Buenavista con la que va de Espinal a Coyutla.

\footnotetext{
${ }^{2}$ Véase plano definitivo del Ejido, aprobado por el Cuerpo Consultivo Agrario el 5 de enero de 1962, en su carpeta básica.

${ }^{3}$ Información proporcionada por don Porfirio Bastián García, la persona más longeva del ejido, quien a sus 103 años mantiene la lucidez, entrevistado el 30 de agosto de 2017 en Buenavista, Veracruz.
} 
Este caso adquiere rasgos de lo que Ramón Ramírez (2002) denomina "redes de lugares y solidaridades”, en alusión a los lugares que se ocupan, se apropian, y las solidaridades y estrategias para defenderlos en pos de la apropiación y defensa del territorio en disputa. La apropiación del territorio y de sus recursos configura una identidad basada en el establecimiento de las relaciones que a continuación abordaremos.

\subsection{El acceso a los recursos y manejo del territorio}

Resultado de las relaciones en torno a la tierra como medio de producción, cuando los ahora habitantes de Buenavista eran peones y de su inserción en las luchas por la tierra que se dieron en la región durante el movimiento agrarista, irradiado desde Espinal, que funda el ejido Pacífico como el primero en el Totonacapan (Ramírez, 2002). Al estar desposeídos y relacionarse con líderes agraristas de Comalteco y campesinos sin tierra que: "llegaron recomendados por personas que ya vivían dentro de la comunidad" (Muñoz y otros: 67), se refugiaron en la montería y se posesionaron como arrendatarios, para más tarde, demandar su derecho a la tierra y fundar el ejido Buenavista.

Todo ello configura un territorio y relaciones sociales y productivas que han posibilitado a los totonacos tanto el manejo y apropiación de los recursos naturales, como la recreación de un estilo de vida que, hasta la fecha, les da identidad como skujnin xala katukuxtu (trabajadores del campo), es decir, gente trabajadora, y la autodenominación de limaxkgan (somos los pobres, huérfanos), términos ambos que reflejan su condición social de campesinos. ${ }^{4}$

Algo que paradójicamente consolida la base económica de la comunidad y la apropiación de una pequeña parte de su territorio y recursos, es la "recuperación" de la parcela escolar, luego reasignada por la Asamblea General Ejidal, y desde entonces trabajada y administrada por el Comisariado Ejidal. Con los ingresos obtenidos por la venta de la producción de naranja ahí cultivada, se otorgan apoyos a todas las escuelas y, además, se destinan algunos recursos para pequeñas obras de beneficio colectivo, así como a eventos y fiestas patronales.

La organización económica descansa más en las estrategias comunitarias, que en una organización formal, promovida desde fuera por las instituciones de desarrollo. En los grupos de mano vuelta, integrados para "prestarse días" y "echarse la mano" - en terrenos ajenos, a cambio de comida y reciprocidad cuando quien presta trabajo lo requiera-, se promueve el

\footnotetext{
${ }^{4}$ Jorge Tino, totonaco, hablante y estudioso del tutunaku, plantea que en la sierra de Papantla y sus colindancias con el Totonacapan poblano, limaxkgan es el término que los totonacos emplean para su autodenominación y comunicación personal. Mientras que para Crescencio García Ramos, lingüista totonaco, hablante de la variante de la costa, la autodenominación es litutunaku: habitantes de tierra caliente y de los tres corazones (García Ramos, 2016: 8).
} 
trabajo colectivo en torno a la parcela ejidal y la maximización de la mano de obra prestada por la unidad familiar, pero ello no trasciende más allá del ámbito comunitario, para insertarse en la organización económica regional de manera más favorable.

El punto de partida para la exigibilidad de los derechos de Buenavista, como pueblo desposeído, fue la demanda por la tierra que le permitió subsistir y desarrollar valores: la cooperación vecinal y familiar; la reciprocidad; el arraigo a su territorio al desarrollar una identidad étnico-campesina, mediante la sociabilidad en su lucha por la posesión de la tierra (De la Peña, 2004), cuestión que lo impulsa a actuar políticamente y en libertad con respecto a la apropiación de su territorio.

Según profesionistas litutunaku, para los "auténticos totonacos" - en alusión a quienes siguen practicando sus costumbres, saberes y valores-, la organización comunitaria tiene entre sus objetivos la recuperación de espacios en diversos ámbitos, el fortalecimiento de sus manifestaciones culturales, saberes, usos y costumbres, para difundirlos entre la población totonaca, a fin de que ésta les dé continuidad, mediante su respeto y práctica, en un "proceso de integración a la sociedad nacional" desde una perspectiva intercultural, que la inserte en "las transformaciones, a la luz de la globalización contemporánea” (García y García, 2016: 9).

Por ello, para su integración económica, los totonacos cambian los patrones de cultivo: introducen cítricos porque se dan cuenta de que generan ganancias, y porque con éstos la tierra ni el medio ambiente atraen plagas ni enfermedades; sin embargo, su manejo se basa en agroquímicos que, a la larga, crean resistencias en el suelo e incluso en las plagas mismas. La lógica mercantil los envuelve en una relación de dominación/sumisión (Gasché, 2008), y la relación armoniosa con la naturaleza no es plena; lo que hace poco sustentables los patrones de cultivo y los modelos de crecimiento económico.

De lo anterior se desprende que, desde hace tiempo, algunos actores y dinámicas socioeconómicas en el Totonacapan se insertan en la modernidad y en relaciones capitalistas, con ganadería y cultivos de vainilla, chile, café e incluso hoja de maíz, a través de esquemas innovadores para la mejora de sus procesos productivos desde una "óptica" de rentabilidad (Ramírez, 2002).

A pesar de ello, cuando en los años 90 se registraron daños provocados por ratas de campo, la comunidad recurrió a creencias religiosas para su control y reforzó su religiosidad al invocar una de las reinterpretaciones del "Santo Tierra", originalmente asociado al Santo Entierro (Guadarrama, 1987). El señor Emilio Pérez acudió hasta el santuario del Padre Jesús, en Jalacingo, Veracruz, para mandar a oficiar una misa y pedirle protección contra los efectos de las ratas de campo, que dañaban las milpas y otros cultivos. ${ }^{5}$ Dicha plaga disminuyó, pero la

\footnotetext{
${ }^{5}$ Platica con Miguel Sánchez, catequista de la capilla de Buenavista el 2 de agosto.
} 
devoción al "Padre Jesús" continúa y se ha convertido en la segunda mayordomía y fiesta comunitaria de importancia.

Así, el trabajo agrícola, asociado a prácticas religiosas y estrategias de subsistencia económica, se convierten en mecanismos de adaptación a nuevas formas de producción y pertenencia identitaria para el impulso de la acción colectiva, donde la solidaridad laboral y ceremonial se materializa en relaciones de reciprocidad para el bien común, a partir de la confianza y la cooperación:

por una parte, todo lo que realizan como miembros de las organizaciones de productores con sus empresas sociales (más bien proyectos); se trata de estrategias consensadas para enfrentarse al sistema económico y al sistema institucional. Por otra parte, están los rituales como miembros de hermandades de los santos y mayordomías que tienen que ver con la organización de las fiestas del calendario religioso (Ramírez, 2002:458).

\subsection{Tipos de solidaridad presentes en Buenavista}

Las formas de solidaridad que se practican en Buenavista, siguiendo a Bertely (2007), son de carácter laboral y ceremonial: "definiéndose la solidaridad no únicamente como el apoyo que una persona debe brindar a otras, sino a partir de una práctica intencional que se funda en la reciprocidad: dar y recibir a cambio y voluntariamente" (p. 39).

Respecto a la solidaridad distributiva, si bien se enmarca en la cooperación, en el dar para recibir a futuro, entendida como una distribución de recursos entre los miembros de los grupos que interactúan, no se presenta en este sentido. Lo que podría ser una expresión de ella es el trabajo en común que se invierte en la parcela ejidal, para luego redistribuir los ingresos de la venta de la producción hacia escuelas y comités que requieren recursos para alguna obra; en ese sentido, se busca el bien común.

\subsubsection{Solidaridad Laboral: faena y mano vuelta}

La solidaridad laboral, entendida como la red de relaciones para "echarse/darse la mano" en las labores y los lugares, se sigue practicando, aunque hay una tendencia a la baja. Están presentes dos modalidades; una de ellas de alcance comunitario, mediante la faena en proceso de desuso por la entrada de programas gubernamentales: PROSPERA y antes el Programa de Empleo Temporal, que han incentivado la participación a cambio de apoyos económicos, y por lo mismo resultado contraproducentes: la gente interpreta que la aportación comunitaria en especie que antes se tributaba mediante faenas, ahora puede cubrirla el gobierno. 
Aquí así estábamos antes, cuando yo empezaba a dar faena, era porque tenía mayoría de edad, aunque no tenía esposa, pero últimamente los jóvenes no quieren hacer faena. Esto empezó a sentirse cuando entró PROGRESA, hace como más de 20 años, antes la gente todavía participaba. (...) De hecho ahorita ya no se puede sancionar a cualquier persona, no se multa, antes el que no iba a dar faena, se iba "al bote", hoy no, si, lo metemos al bote porque no participa y no da faena, a lo mejor nos van a meter a nosotros, por eso de los derechos humanos (Entrevista a Alberto Bastián Pérez, subagente, julio 7 de 2017).

La participación comunitaria ha disminuido, mediante una de las formas de organización para el trabajo en beneficio de la comunidad: la faena, debido al impacto de programas sobre el tejido social, aunado a la pérdida paulatina de coercitividad del sistema normativo comunitario, que resta competencias para normar la organización comunitaria y acelera el proceso de individualización en las comunidades. La falta de confianza en la autoridad, por la sanción ejemplar y multas que imponía a quienes no daban faenas, derivó prácticamente en una desestructuración de la faena como institución propia de las comunidades totonacas, al incentivar la participación, vía programas gubernamentales ( $C f r$. cita de Masferrer, 2004, p. 7), y equipararse la faena con el trabajo forzado; esto último por parte de las autoridades municipales y de la Comisión Estatal de Derechos Humanos.

Sin embargo, resulta interesante la lectura de las autoridades comunitarias sobre la forma como se ha desvirtuado la participación de la mujer en los programas que la focalizan para otorgarle apoyo; cómo el hombre considera que si su mujer asiste a las reuniones recibirá todo tipo de información que antes le era trasmitida a él, pues en la actualidad el programa PROSPERA tiene que ver con las principales actividades para el acceso "condicionado" a los servicios que la mayoría de las comunidades tiene: educación y salud, y en algunos casos comedores comunitarios o desayunos escolares.

\footnotetext{
Ahora las que más participan son las mujeres de PROSPERA porque los hombres ya no quieren participar, [sólo] cuando se les pasa la lista como asistencia a sus mujeres de PROSPERA para considerarlas y no multarlas, pues son 140-150 pesos. (...) Lo que ha venido a cambiar, fue el programa de PROSPERA porque muchos compañeros empezaron a pensar que [sí] las mujeres les avisan de lo que se trata, ellos no participan. Por una parte PROSPERA vino a apoyar pero por otra a desintegrar la comunidad, la gente ya no quiere hacer faenas (Entrevista a Alberto Bastián Pérez, subagente, julio 7 de 2017).
}

No obstante, sigue predominando la idea de que la mujer no debe realizar "trabajos fuertes", sólo actividades de saneamiento ambiental: encalar, barrer y recoger basura. Cuando se trata de hacer faena para chapear, limpiar terrenos, caminos, etc., los hombres acuden -no por voluntad propia o por servicio a la comunidad haciendo faena-, pero a cambio de que sus 
mujeres no sean multadas o se les retire del programa. ${ }^{6}$ Esto ha llegado al grado de que en varias comunidades, faenas y reuniones, las mujeres son convocadas en coordinación con las vocales de PROSPERA, porque sólo de esa manera asiste la mayoría.

Lo anterior revela el aumento de la participación de la mujer en los asuntos comunitarios, incluso en Buenavista han ocupado cargos importantes: agente municipal (20072010), secretaria del comisariado ejidal, presidentas de diversos comités de gestión comunitaria, y han sido mayordomas; entre otros factores, lo ha facilitado: "el hecho de que cada vez un mayor número de ellas saben leer y escribir” (Zenno, 2007:357). Políticamente, en Buenavista han asumido una "militancia disidente", a través de la gestión de proyectos y servicios. Tal situación es parte de la trasformación del sistema de cargos y de gobierno comunitario, debido a la nueva ruralidad y estilos de vida más urbanizados, así como por el alto nivel de bilingüismo (Zenno, 2007).

A pesar de ello, en el fondo vemos cómo se reproduce una relación de dominación/sumisión que se ha interiorizado tanto en el hombre como en la mujer, supliendo a la mujer en la faena por actividad pesada, y la mujer permite que el hombre reproduzca la idea del "sexo fuerte" e incida en las decisiones sobre el destino de los beneficios del programa: "A veces cuando más ayuda el hombre, más se atiene la mujer a él".

Aun cuando en Buenavista las autoridades se someten y consultan a la Asamblea Ejidal, siendo una comunidad "tradicional", los vecinos esperan que ésta "ponga orden"; sin embargo, debido a la "lealtad a las instituciones" que todavía practica una mayoría de éstos en su relación con el gobierno, mediante gestores o intermediaros como los operadores y las vocales de PROSPERA, y en ocasiones por actuación de las autoridades, se reproducen relaciones clientelares que fomentan la dependencia, la subordinación del ciudadano, quien actúa como "súbdito" ante el paternalismo del Estado, lo que afianza una dominación patrimonial:

la desconfianza es la precondición del ciudadano que se comporta como súbdito; como aquel que solo espera recibir; que renuncia a influir, a demandar; que es incapaz de asociarse con otros ciudadanos para resolver sus problemas, y para defender sus demandas y exigir su cumplimiento (Durand, 2004:95).

Ante la carencia de recursos para pagar jornales durante las labores agrícolas que requieren mano de obra intensiva, aún persiste otra modalidad de solidaridad laboral con

${ }^{6}$ El domingo 10 de julio de 2016, la subagencia municipal de Acatzacatl, municipio de Zozocolco, Veracruz, convocó a faena para chapear la carretera. Una vez concluida la faena, el Subagente pasó lista dando los nombres de las mujeres titulares de PROSPERA, pero quienes contestaron fueron sus maridos o hijos que habían asistido a cumplir con el programa. Información propia, obtenida in situ.

${ }^{7}$ Véase relatoría del Taller: "Los nuevos roles de la mujer: Autovaloración, identidad y valores", realizado el 27 de junio en La Casa del Campesino de Buenavista. 
alcance grupal y beneficio familiar y vecinal. La vigencia de la "mano vuelta" se debe a que sus beneficios se notan, se perciben en lo individual; su efectividad radica en la reciprocidad entre quienes conforman el grupo de mano vuelta, al ayudar en el trabajo ajeno; asegura recibir apoyo cuando lo necesita en sus labores, y resulta más fácil excluir del grupo a quien no da reciprocidad, retirándole la confianza.

Resulta paradójico que en un contexto comunitario, regional y nacional de desconfianza hacia las instituciones, ésta no afecte aún la confianza interpersonal, que promueve la colaboración vecinal, la reciprocidad que, en tanto se construye desde la familia y las redes de parentesco y vecinales, genera una articulación grupal. Sin embargo, la confianza interpersonal todavía no se traduce en "un lazo que une a los individuos con la sociedad" (Durand, 2004:95), que genera confianza en las organizaciones externas, al no actuar el ciudadano políticamente con libertad ni por convicción en el espacio público, orientado en valores, sino por negociación en torno a la obtención de obras de infraestructura social en el mejor de los casos, y la mayoría de las veces, por los apoyos clientelares que recibe:

Sin confianza, no existe la participación voluntaria y libre de los ciudadanos para conformar organizaciones que defiendan sus intereses, que articulen sus demandas y que los conviertan en ciudadanos participantes y competentes frente al Estado para lograr la satisfacción de sus intereses (Durand, 2004:94).

Por lo tanto, la participación comunitaria no alcanza una incidencia sostenida para defender sus intereses. La confianza interpersonal todavía no desarrolla un nivel organizativo que trascienda lo comunitario y se convierta el cimiento del consenso organizativo y la democracia regional. El vigor de la confianza interpersonal, expresada en la mano vuelta, puede deberse a que ésta no sólo es un mecanismo para darse la mano, un mecanismo de ayuda mutua en el trabajo, sino para compartir: quien recibe apoyo de los otros está obligado a invitar la comida y la bebida:

De hecho voy a la mano vuelta y al jornal. Cuando (empieza) el tiempo de trabajo en las parcelas: siembra, riego de líquidos y cosecha, se busca el grupo de mano vuelta. Cualquier vecino, amigo, invita o se suma al grupo, se va rolando de terreno, un día a uno y a otro, si no tenemos dinero para pagar, se busca compañeros a mano vuelta. A quien le trabajan, está obligado a dar de comer, el trago. El almuerzo lo lleva el casero (dueño del terreno), la comida es en la casa del casero donde se acostumbra tomarse algo: refresco, cerveza, de agradecimiento que nos estamos echando la mano. Casi la mayoría del pueblo trabaja en mano vuelta, se busca a la gente, a veces aunque haya dinero hay gente que prefiere hacer el grupo de cinco a seis personas porque se avanza (...) la cosa es ayudarnos el uno al otro (Entrevista a Alberto Bastián Pérez, subagente, julio 7 de 2017).

Crescencio García Ramos (2016) considera que la "solidaridad tradicional de la colectividad totonaca" aún subsiste y resiste ante la globalización; la considera una práctica 
cotidiana, no remunerada, del servicio comunitario prestado por la autoridad y los faeneros en beneficio de la colectividad; promueve la participación comunitaria consciente y valores como la unidad, la justicia, el interés colectivo, incluso la participación e identidad en el plano comunal, además de ser un "instrumento de lucha” para enfrentar condicionas adversas y de marginación (p. 8).

En general, coincidimos con esta perspectiva y el "deber ser" expuesto por García Ramos, pero cabe distinguir entre el servicio a la comunidad y la faena. Si la autoridad no recibe una remuneración es por servir a la comunidad, y como parte de su obligación debe encabezar las actividades del trabajo comunitario, entre ellas, la faena. Actualmente, prestar servicio representando a la comunidad, más que prestigio, en varias comunidades totonacas es considerado una "carga", sólo da reconocimiento como responsable; en cambio, dar faena es una colaboración "obligada y sin remuneración del trabajo físico individual en aras del bien común” (Zenno, 2007:355); en ambos casos, el trabajo realizado puede otorgar reconocimiento.

En el primer caso, este reconocimiento se confiere en reciprocidad por la responsabilidad y honestidad mostrada durante el servicio a la comunidad, siempre y cuando su desempeño haya sido "bueno"; en el segundo, por el cumplimiento de la faena como obligación de dar trabajo en beneficio de la comunidad, lo cual, sin embargo, no alcanza a recuperar la confianza en las instituciones y a dinamizar la participación ciudadana, pues ya no "se funda en la reciprocidad: dar y recibir a cambio y voluntariamente" (Bertely, 2007: 39).

Ante un panorama de desestructuración de la participación comunitaria y desmovilización del sistema de cargos entre los totonacos (Masferrer, 2004), el divisionismo provoca que cuando un grupo político gana, sus seguidores sean quienes dan faena (los perdedores se resisten), o bien, que la autoridad condicione las gestiones a quienes lo apoyan, porque la participación es incentivada para ser beneficiarios de los programas.

\subsubsection{Solidaridad ceremonial: fiesta y mayordomía para compartir}

Sin duda alguna, la solidaridad ceremonial es la más practicada en Buenavista, al igual que en varias comunidades totonacas, mediante la mayordomía y ceremonias festivas. Incluso en fiestas familiares y en situaciones de duelo se acostumbra dar LamaKgaxokgo, ${ }^{8}$ una modalidad de apoyo que la gente identifica como mano vuelta en el ámbito doméstico de lo vecinal.

\footnotetext{
${ }^{8}$ Ver relato sobre la organización y patrocinio de una fiesta de bautizo en Coyutla, Veracruz: "La mano vuelta, Lamakgaxokgo, aquí es una tradición de apoyarse; si alguien se muere, hay mucho apoyo aquí, todavía llevan maíz, pollo, jabón, leña, despensa, pues. Igualmente si hacen pachanga, igual te traen refresco, te dan cerveza, pollo, chile ancho, todo lo que se ocupa en la cocina. Si tú tienes deseos de acompañar, vas a ir con los refrescos, cartón de cerveza, o nomás te preguntan ¿y cuándo vas a hacer tu mole? Y te ayudan hacer la comida (García y Hernández, 2017: 15-16).
} 
La mayordomía se concibe como un cargo religioso, pero su influencia y organización se mezcla con los valores civiles en la cotidianidad práctica, como la responsabilidad ante la comunidad, pero también, en el plano espiritual, para estar bien con los "dueños de la naturaleza", para que haya un bien común en que lo principal es compartir a base de cooperación, en efectivo y en especie, durante o después de la mayordomía, lo cual auspicia la obtención de prestigio, aunque prima la fe religiosa. Todo ello motiva una convivencia en el plano ritual e "incluye desde la oración hasta el baile, pasando por la comida y la bebida, y ofrecer su dinero para realizar todo el proceso de las fiesta. (...) negar este catolicismo local significa dejar de ser uno del pueblo" (Zenno: 2007:358).

La fe se convierte en un elemento central para pasar del actuar individual con responsabilidad, a desarrollar un nuevo tipo de responsabilidad, espiritual y colectiva ( $C f$ r. cita de Urías, 1987, p. 7), donde destaca un rasgo genérico positivo: ${ }^{9}$ la "cera", característica de la cultura y religiosidad totonaca:

La verdad es tener fe, agradece uno a la virgen para tener salud para la familia; para que le vaya bien al pueblo, para que haya buena cosecha, se entrega la cera. Por eso es la responsabilidad de entregarla, de cooperarse. Van a ver señores de Anayal Uno que hacen la cera, él pide la cera y hace las velas y cirios, y los decora en la casa. Hay que tener fe y ganas de entregar la cera; uno se da a conocer con la gente de la comunidad y de otros lados, de cómo es la fiesta, lo invitan a uno, saben que se participa y comparte, en ese sentido se da uno a conocer (Entrevista a Alberto Bastián Pérez, subagente, julio 7 de 2017).

Vemos, en el fondo, mecanismos implícitos en la obtención del prestigio, a través de la organización/realización de una "buena fiesta", y la decoración y abundancia de la cera, y su entrega no sólo al santo el día de su fiesta patronal con motivo de la mayordomía, sino también a los futuros mayordomos (Segura, 2008). Simbólicamente, con ello se reproduce las condiciones de bienestar para todos, es decir, para la comunidad, al asegurarse la trasmisión del "alumbre" -mediante la cera fundida para ser entregada y reutilizada en la ofrenda al santo patrono el año siguiente - por el próximo mayordomo. Las velas que se dejan y guardan, se utilizan para prenderlas cuando algo malo suceda:

Los cirios son de un metro, son de cuatro cirios. La cera se trae de la casa del mayordomo con cirios y velas. El padre bendice la cera, se pasa a la iglesia y empieza la misa. Entonces están prendidas o encendidas toda la noche, y al otro día se llevan al que será mayordomo en el año siguiente. Tiene que estar seis días en el altar de su casa y luego se desbaratan los cirios, y sólo las velas se quedan para cualquier evento que se realice o prenda cuando hay mal tiempo, alguna enfermedad, se vaya a

\footnotetext{
9 “Los rasgos genéricos de la sociedad indígena nos permiten identificar diferencias tipológicas en relación con la sociedad no indígena - llámese sociedad nacional, occidental o urbana- y entre los estilos de vida que rigen ambos mundos de vida" (Bertely, 2007:36).
} 
sembrar o cuando sucede alguna cosa mala, se prende la vela, supuestamente la vela prendida sirve para alejar algo malo (Entrevista a Alberto Bastián Pérez, subagente, julio 7 de 2017).

Mantener el "alumbre" con la cera se convierte en una responsabilidad individual del mayordomo, quien al sostener una institución comunitaria de carácter religioso (la mayordomía), cumple también con una responsabilidad espiritual hacia su familia y comunidad: brinda seguridad alejando al mal o venerando al santo patrono para pedir una buena cosecha o por la salud de la familia. Así, durante la mayordomía se evidencian valores tales como compartir y cooperar, característicos de la solidaridad ceremonial y que se convierten en praxis, a través de una resistencia cultural que promueve otro tipo de relaciones, alejadas del egoísmo, y redistribuye lo acumulado mediante el consumo ritual.

Pese a la pérdida paulatina de la ritualidad, en Buenavista la práctica de la danza se mantiene como rasgo específico. ${ }^{10}$ Llama la atención que siendo una localidad pequeña, conserve tres danzas: "Tejoneros" (Xcutis), "Negritos de la costa” y "Guaguas”. Alrededor de la danza y su ejecución para su religiosidad, festividad y recreación identitaria, en 2017 se organizó un evento de carácter regional: el $5^{\circ}$ Encuentro de Danzantes del Totonacapan, durante la fiesta patronal de Buenavista, cuya celebración encierra desencuentros sobre su costeo, pero también resalta la importancia de la danza y de los valores comunitarios:

\begin{abstract}
Muchas personas yo las escucho, dicen que por qué no se había hecho antes, critican que el comisariado quiera agarrar de la parcela escolar. Si se va a hacer el Encuentro, por eso cooperamos. Hay muchas críticas, pero es más la gente que está a favor. Los hermanos dicen que por qué van a cooperar, si ellos cuando hacen algo no le piden a los demás, pero la cooperación no es para la religión, es para la comunidad, todos deben cooperar, por eso somos una comunidad (Entrevista a doña María Antonia Sánchez Cruz, ex subagente, julio 7 de 2017).
\end{abstract}

Este comentario no sólo ilustra sobre la importancia de la danza y la organización comunitaria, sino también acerca de la práctica de valores que caracterizan a la comunidad; la cooperación, por ejemplo, da sentido de pertenencia; quien coopera es parte de la comunidad: “todos deben cooperar, por eso somos una comunidad”, con ello se enfrentan los problemas, pero también se costean las fiestas. Así, al participar como patrocinador, al cooperar o ser directamente el mayordomo, e incluso al danzar se reproduce la identidad étnica, se obtiene prestigio y relaciones con una amplia red de parentesco ritual; todo ello otorga autoridad moral (De la Peña, 2004).

4. IDENTIDAD ÉTNICA Y APROPIACIÓN PRÁCTICA DE VALORES

\footnotetext{
${ }^{10}$ Jorge Gasché (2008) se refiere a los rasgos específicos, en contraposición con los rasgos genéricos, como variante del tipo de sociedad (por ejemplo, la sociedad indígena), que permiten identificar una "experiencia particular en determinado pueblo" (p. 368).
} 
La identidad étnica y la autoestima de los totonacos han sido construidas en relación con su territorio y la recreación de sus prácticas culturales, pero también en su relación con la sociedad nacional, como parte de un proceso construido en la cotidianidad de "la vida totonaca, latamat", mediante principios y valores como la confianza, la hermandad, la seguridad y la unidad:

La vida totonaca, latamat, es un proceso largo que no se detiene, un camino donde se mantiene la confianza, la hermandad y la seguridad como pueblo originario. Donde se mantiene la firmeza, la seguridad, la fortaleza, la forma tradicional, la relación con sus deidades creadoras (naturales y sobrenaturales), que son atributos en los cuales conserva su unidad e identidad colectiva. Recuperar y mantener la forma tradicional sobre el aprovechamiento de la madre naturaleza es un principio fundamental (García y García, 2016: 9).

Mantener la confianza, la hermandad, actuar con firmeza y seguridad, como pueblo, requiere de la unidad y de una "identidad envolvente" que una y a la vez diferencie a los pobladores en lo colectivo. Entre los totonacos de la sierra, limakxtim (unión), esto se considera un principio:

limakxtim que se interpreta como unidos-unión, pero a la vez, el significado de esta palabra conlleva a la integración de la población, y a la promoción de la participación y organización, que se da en situaciones de conflicto, de las cuales emergen actores y de cómo éstos pueden constituirse en sujetos que enuncien o apropian una propuesta (Cortez y Francisco, 2017:35-36).

La unidad se convierte en un medio para organizarse que permite a la comunidad renovarse mediante la consolidación de un proyecto de trabajo con objetivos claros y en la medida que se practiquen principios y valores. Si se logran los objetivos y se practican los valores se mantendrán unidos, habrá limakxtim para enfrentar situaciones diversas e incluso conflictivas, más que la unidad:

La organización se destaca porque siempre ha querido la unidad, un orden renovado en comunidad, en lo social, en lo cultural, en lo económico, en lo político, en lo religioso, en la biodiversidad con el objetivo de ir cristalizando y consolidando un Proyecto de trabajo estratégico, conforme vayan desarrollándose los principios y sus objetivos a corto, mediano y largo plazos (García y García, 2016: 9).

Los valores, como "prácticas sociales" entre los totonacos han sido indagados a partir de la realización de talleres de reflexión, tanto con hombres, como con mujeres, pero por separado. En ambos talleres se inició con la dinámica de pulseras para la presentación; consiste en la escritura, por parte de cada participante, de una palabra que caracterice su actuar, pensar 
o forma de ser en la pulsera que llevara puesta durante todo el taller. Esta dinámica sobre lo característico de una persona permite reflexionar acerca de los valores que se practica (Del Amo, Vergara, Ramos, 2014).

En el caso de los hombres, un valor reflejado en sus propias palabras que podríamos considerar es "serio", en el sentido de "seriedad" en su actuación y compromiso, pero, en términos generales, las palabras expresadas hacen alusión a características específicas de cada persona. Algunos se definieron como "danzantes" en activo o porque lo fueron; éstos asocian la danza con el optimismo, la alegría. En la reflexión sobre cómo estas palabras guían sus actuaciones, pensamientos, comportamientos, los participantes expresaron: "nos damos cuenta cómo estos valores nos ayudan a trabajar, danzar y producir". "Tenemos que ser serios, optimistas, puntuales y trabajadores para hacer una buena danza". "Uno tiene que ser trabajador para que la cosecha se dé". ${ }^{11}$

Cuando se aplicó el mismo ejercicio con las mujeres, se corrigió y trató de que cada una escribiera por separado la palabra que la caracteriza, para evitar la repetición de términos, como sucedió en el taller con los hombres. Aun así se repitieron algunas palabras. Además, se analizó si la palabra era un valor o una característica - ejercicio que no se hizo con los hombres-, destacando que ellas sí identifican como valores responsabilidad, paz y comprensión.

Palabras que caracterizan a los/las participantes

\begin{tabular}{|lll|l|}
\hline \multicolumn{3}{|c|}{ Mujeres } & \multicolumn{1}{c|}{ Hombres } \\
\hline Seria y puntual & $\ldots \ldots$ & Característica & Optimista (2) \\
\hline Inteligente $(2)$ & $\ldots \ldots$ & Característica & Serio (2) \\
\hline Responsable & $\ldots \ldots$ & Valor & Danzante (3) \\
\hline Paz (de Pacífica) & $\ldots \ldots$ & Valor & Puntual (2) \\
\hline Comprensiva & $\ldots \ldots$ & Valor y característica & Trabajador (2) \\
\hline Participativa & $\ldots \ldots$ & Característica & \\
\hline Capaz & $\ldots \ldots$ & Característica & \\
\hline Alegre $(2)$ & $\ldots \ldots$ & Característica & \\
\hline
\end{tabular}

Al analizar "la vida totonaca, latamat", encontramos, implícita, la práctica de valores que hacen alusión al servicio a la comunidad, a compartir en reciprocidad, a la participación. La identidad se construye e identifica con la pertenencia a la comunidad por sus vínculos con el campo adonde trabajan para sobrevivir -incluso se consideran skujnin xala katukuxtu: trabajadores del campo-, con el ser hablantes de la lengua totonaca y con la danza.

${ }^{11}$ Ver Relatoría del Taller: “Autoestima étnica e identidad”, realizado el 5 de noviembre de 2016. 
La reflexión en los talleres derivó hacia quiénes son los totonacos, lo que llevo a una discusión sobre el ser (como sinónimo de pertenecer) y sentirse, a partir de las preguntas ¿qué se siente ser totonaco? y ¿se debe ser o sentirse totonaco?

- Para sentirme totonaco, debo hablar totonaco.

- Sí, soy totonaco, pero no me siento de aquí.

- Puedo venir de otra parte, pero yo me siento totonaco.

- Yo creo que debe uno sentirse totonaco.

- Se siente uno orgulloso, porque lo habla (el tutunaku) uno.

-No sólo son los que están aquí, también los que se van llevan sus raíces y no dejan de ser totonacos.

- Hay quien sí se avergüenza de hablar totonaco; luego se avergüenzan, pero siendo mexicanos todos somos indios, somos totonacos. Les da pena, porque les pueden decir nacos, indios.

- Hay unos que sienten orgullo, otros que les da pena, se desprecian a sí mismos.

- Si uno tiene orgullo por hablar la lengua, se siente uno todo el tiempo totonaco. ${ }^{12}$

Interesantes juicios todos, que van desde el desarrollo de una identidad en migración, pasando por la introyección de una relación de dominación/sumisión: vergüenza por hablar la lengua materna, por adscribirse a una identidad étnica; timidez ante la autoridad, sentimiento de inferioridad ante el opresor, y "reacciones sicológicas" de carácter subjetivo, manifiestas en la conducta de las personas indígenas, que revelan la sumisión ante un mestizo dominante (Gasché, 2008: 372-373) y el impacto que ello produce en la autoestima, hasta destacar el orgullo étnico, a partir de la lengua como núcleo de originalidad y marcador de límites y diferencias al ser, sentirse y pertenecer. Todo ello conduce a los totonacos a una adscripción de skujnin xala katukuxtu (trabajadores del campo), pero también a la autodenominación limaxkgan (somos pobres, campesinos).

\subsection{Patrimonio cultural y apreciación de valores por los "profesionistas litutunaku"}

Una vez indagados en talleres de reflexión, a continuación contrastamos los valores practicados por los totonacos de Buenavista y sus formas de ser, con lo planteado por profesionistas litutunaku (totonacos de la costa), respecto a la apropiación y comprensión, antes narrada, entre los limaxkgan (totonacos de la sierra).

Para el antropólogo indigenista Domingo García (2016), totonaco-hablante, la "revolución cultural" vivida en el Totonacapan es producto de la mezcla de sueños de quienes lo habitan y de quiénes llegaron de fuera; de un mestizaje cultural que se refuerza con la dinámica socioeconómica, amalgama de la actividad agrícola (vainilla, café; citricultura),

\footnotetext{
${ }^{12}$ Relatoría del Taller: "Autoestima étnica e identidad”.
} 
ganadera y la industria regional, y que abre "pequeños resquicios de oportunidades" (p. 37), creadas por las acciones productivas, socioculturales y políticas que involucran a los totonacos.

También para García Ramos (2016), lingüista totonaco-hablante, el desarrollo modernizante impulsado por un sincretismo cultural los ha influenciado mutuamente, pero debe sostenerse, para "sobrevivir en diversidad", como pueblos "antiguos pero contemporáneos":

Pero a pesar de ello, los totonacas vivimos, sobrevivimos en tierras aún fértiles, como pueblos originarios, antiguos pero contemporáneos, donde ha germinado el producto sincrético de tres culturas: la mesoamericana, la africana y la occidental, con dignidad y respeto. Claro, hemos recibido influencia de hombres y mujeres que, al correr de la historia, ha dejado constancia espiritual fuerte, auténtica e indeleble, que está en la conciencia de muchas generaciones de totonacas y no totonacas hasta la actualidad. Ojalá que esta historia sea sostenida para siempre (García Ramos, 2016: 8).

Los totonacos coexisten y conviven entre dos modelos civilizatorios: el mesoamericano y el occidental, que inciden en la planeación del desarrollo y la mejora de las condiciones de vida, el segundo más que el propio, aunque los desestabiliza, ante lo cual resisten para evitar que el modelo dominante devaste su propio modelo (García García, 2016). Sueñan "utópicamente", se consideran cósmicos y globales, insertos en la modernidad, al ser parte del patrimonio cultural de la humanidad:

Soñamos utópicamente, y sobre esta concepción trabajamos vastos sectores de este territorio cósmico (...). Somos cósmicos compartiendo saludablemente con la concepción moderna, vivimos tiempos de grandeza y de internacionalización, con tres patrimonios culturales de la humanidad reconocidos por la Organización de las Naciones Unidas para la Educación, la Cultura y la Ciencia (UNESCO): Ciudad Sagrada de El Tajín, Ceremonia Ritual de Voladores y el Centro de las Artes Indígenas y de las buenas prácticas educativas del arte y su cultura. Éstos nos acompañan en los nuevos procesos de acomodamiento del pueblo totonaco en esta globalización (García García, 2016:37).

Además de la patrimonialización de su cultura, ya reconocida por la UNESCO y apropiada por los organizadores y promotores de la Cumbre Tajín, Domingo García (2016) identifica otros elementos de la cultura totonaca: la dulce lengua totonaca, el arte totonaco expresado en la danza; la música ritual, la alfarería de la sabia tlawaná; la gastronomía y el telar de cintura, donde su hacedora, la tlahuaná, tejerá "lienzos de nudos" para expresar símbolos que guarden el conocimiento a reinterpretar por las nuevas generaciones, que harán cumplir la profecía del mundo feliz y el bienestar donde cada hombre: "tendrá su vocación y una misión que cumplir en los tiempos venideros” (p. 38).

Al reflexionar sobre cómo la filosofía del arte totonaco lleva a la realización del espíritu, mediante la práctica de la danza del volador y el significado de la misma, Domingo García (p. 38) sostiene que actualmente es invocada por sus nuevos ejecutantes; aunque se 
moderniza, se mantiene su práctica. Mientras tanto, cada nakupolitano (totonaco) se prepara para la vida, para articularse con la modernidad y la sociedad nacional, y a la vez que danzante, curandero, artesano, campesino, es un nakupolitano moderno.

Vemos entonces cómo profesionistas litutunaku reivindican lo moderno para insertarse en la globalización, reflexionando sobre los "elementos valiosos de la cultura totonaca”, reforzando su idea de coexistencia con el modelo civilizador occidental, pero a la expectativa de que no los desestabilice y lograr una convivencia más armoniosa. Ante el reto de la articulación sociocultural e integración económica, y como nuevos intermediaros entre los pueblos y el Estado, enfrentan un dilema: "pero los indios que hemos estudiado sabemos que si todos nos quedamos en casa no nos podremos defender". ${ }^{13}$

Según García Ramos (2016), los litutunaku han sido relegados a la ignorancia por la modernidad que desde el sistema educativo nacional se promueve, y no sólo por la realidad comunitaria, social y cultural contemporánea que enfrentan. Reconoce que han sido subordinados, y por lo tanto algunos se autodesprecian, no obstante que son creadores de patrimonio cultural y portadores de valores, lo que los coloca en una crisis de identidad. A pesar de ello, mantienen la responsabilidad de revalorar su memoria histórica y sus saberes, desde su propia cosmovisión, en relación con su territorio y la madre naturaleza:

\begin{abstract}
Somos los que hemos evidenciado nuestro acervo cultural material e inmaterial, somos los creadores y portadores de los valores, y por el hecho de saber que hemos sido conquistados, subestimados, devaluados, martirizados, sometidos a crueles persecuciones, hemos terminado por autodespreciarnos, al mismo tiempo que rechazamos y negamos nuestra verdadera identidad, conocimiento y sabiduría milenaria.
\end{abstract}

Tenemos como alta responsabilidad y compromiso recuperar nuestra memoria histórica, cúmulo de conocimientos y sabiduría tradicionales (...) así como el esfuerzo y la reserva de las prácticas sustentadas en los conocimientos de nuestros abuelos fundadores de pueblos, lenguas y culturas, con aquel sentimiento y deseo apasionado que vivieron y emprendieron, al sentir el palpitar de nuestra sagrada Madre-Abuela-Tierra: Kintsik'án-Tsiyuna-T’iyat... (García Ramos, 2016: 7-8).

Pese a todo lo anterior, los profesionistas totonacos señalan la importancia de "sobrevivir en diversidad", en un contexto intercultural y multilingüe que da fundamento a su identidad recreada por sus pueblos y comunidades en plena contemporaneidad. "A la luz de las transformaciones de la modernidad", reivindican los aportes de su cultura al desarrollo mesoamericano, en un marco de convivencia en "diversidad cultural” (García Ramos, 2016: 7) que revalore el patrimonio totonaco para la mejora de su calidad de vida.

Bajo este enfoque de patrimonialización, los valores parecen orientar el desarrollo cultural de los totonacos, más en el plano de lo que Weber (1984) relaciona con "la belleza,

${ }^{13}$ Ver testimonio de un profesionista huichol en De la Peña (2004:30). 
la sapiencia religiosa, la piedad", que con "la dignidad (...) o la trascendencia de una causa" aunque la defensa del patrimonio sin duda lo es, la objeción está en los fines- que abone también a la convivencia intracultural, la cual, a nuestro juicio, debiese consolidarse como estrategia para la interacción en la diversidad político-sociocultural que hoy viven las comunidades totonacas, como Buenavista, frente al otro, la nación, potenciada por la globalización, es decir, que promuevan la articulación del tejido social (Durand, 2004) y orienten la construcción de ciudadanía, vinculando los valores de la cultura con el derecho, e incluso entender el derecho propio como parte de su cultura, sin desvincular los derechos culturales de los civiles, políticos y sociales (De la Peña, 2004:38).

Apostar a la patrimonialización de la cultura, para insertarse en la modernidad, puede implicar el riesgo de asumir posiciones transculturales que desdibujen el propio modelo de desarrollo, y sólo se aprehenda de los rasgos externos sin resaltar lo originario, con base en un enfoque intercultural que favorezca la convivencia en la diversidad y permita insertarse en la modernidad desde una "regionalidad construida", tal como alertan García Ramos y García Flores (2016), quienes observan que los procesos de integración a la sociedad nacional, en un marco de globalización, deben dar pie en el Totonacapan a procesos de revaloración de los propios valores y de reconocimiento y tolerancia entre mestizos y totonacos:

Este proceso tiene dos tendencias: uno, los mismos totonacos están reconociendo sus valores propios $\mathrm{y}$, dos, las comunidades mestizas también van reconociendo y aceptando dichos valores totonacas y, en esta misma dimensión, se van estableciendo los mecanismos de reconocimiento, de tolerancia e identidad, propios de los habitantes tanto de los totonacas como de los no totonacas, para ser mejores en convivencia intercultural en el territorio del Totonacapan (García y García, 2016:9).

\section{REFLEXIONES FINALES SOBRE LOS VALORES EN Y PARA LA GESTIÓN TERRITORIAL}

En términos generales, al revisar entre los totonacos de Buenavista el proceso de recreación identitaria y la práctica de valores, vemos cómo éstos contribuyen a configurar rasgos identitarios, genéricos y específicos, en relación con el territorio, al incluir la comunidad, como el espacio donde se desenvuelven, pero también una sociabilidad y una condición social: el ser limaxkgan (campesinos). Aunque los totonacos asocian lo étnico con lo racial y lingüístico, perciben sus diferencias como resultado de la diversidad, de modo que piensan que éstas no deben dividirlos en la búsqueda del bien común; tratan de mantener la limakxtim (unión), la cual deben facilitar tanto la lengua como sus raíces.

Mientras la reciprocidad asegura una colaboración voluntaria, reforzada por la confianza en las relaciones interpersonales ancladas en las "vivencias prácticas" desde la 
familia, la cultura y la religiosidad de los totonacos, la penetración de los programas gubernamentales erosiona las instituciones comunitarias y sus liderazgos, y ello disminuye la colaboración de los pobladores con sus autoridades.

El divisionismo político acrecienta la desconfianza en las instituciones gubernamentales, no obstante que una mayoría ha asumido una militancia disidente como "resistencia activa a los mecanismos de dominación y sumisión” (Bertely, 2007:43) y disputa el poder e incluso gobierna en el plano comunitario. La dominación patrimonial, mediante prácticas clientelistas que refuerzan la lealtad a las instituciones estatales, genera que la mayoría pasiva actúe de manera condicionada para mantenerse como beneficiaria y se subordine, al no participar libremente en los asuntos públicos por temor a perder apoyos, lo que también limita su inserción voluntaria a procesos organizativos que trasciendan lo comunitario.

$\mathrm{Si}$ bien la configuración de una "identidad envolvente" disminuye tensiones desorganizativas, poner en práctica la tolerancia, mediante la discusión de asuntos de interés grupal y colectivo en las reuniones de trabajo y asambleas comunitarias, conduce a que poco a poco se le asuma, de manera reflexiva, como un valor apropiado, aunque aún no termina por interiorizarse y se expresa como una tolerancia pasiva (Durand, 2004), como una “acción de sobrellevar" que implica resistencia y resignación a la vez (Hernández, 2007:11 12).

Los valores resultan influenciados por la interacción cotidiana de los totonacos con la nación, en el Totonacapan, región con una integración económica y una articulación sociopolítica y cultural en condiciones de asimetría, y por una aspiración de coexistir en la modernización y la globalización, como hacedores de un patrimonio cultural que se folkloriza desde el Estado, mientras algunos actores promueven su reivindicación por la vía patrimonialista. Sin embargo, los valores deben ser retomados como orientadores de la acción social para construir ciudadanía, ligando la cultura con los derechos; en ello, los profesionistas deben desempeñar su capacidad de agencia de valores "propios y apropiados", en ese orden, para defender su cultura a partir de los derechos.

\section{REFERENCIAS}

Alafita MÉndez, L. (2012). Tolerancia y democracia: los valores políticos en Veracruz. En Aguilar SÁnchez, M. (Coord.), La difícil construcción democrática en Veracruz. Acceso a la justicia y actores sociales (pp. 85-127). Xalapa: Universidad Veracruzana (UV). 
Bertely Busquets, M. (2007). Conflicto intercultural, educación y democracia activa en México. Ciudadanía y derechos indígenas en el movimiento pedagógico intercultural bilingüe en Los Altos de Chiapas, la Región Norte y la Selva Lacandona de Chiapas. México: Centro de Investigaciones y Estudios Superiores en Antropología Social (CIESAS), Fondo Editorial Pontificia Universidad Católica del Perú.

Blanco rosas, J. L. (1987). Territorio y política. En Urías Hermosillo, M. (Coord.), Coxquihui, Chumatlán y Zozocolco de Hidalgo: Tres municipios totonacos del Estado de Veracruz. (Historia y realidad actual: 1821-1987) (pp. 149-258). Xalapa: Coordinadora Estatal de Veracruz, Instituto Nacional Indigenista. Mimeografiado.

Cisneros, I. (2007). Tolerancia y democracia. México: Instituto Federal Electoral (Cuadernos de Divulgación de la Cultura Democrática, 10).

Cortez Antonio, J., Francisco LÓpez, S.D.N. (2017). Modos organizativos y gestión integral del agua para su abasto, almacenamiento, suministro y distribución en una comunidad totonaca de Filomeno Mata, Ver. Tesis de Licenciatura en Gestión Intercultural para el Desarrollo Espinal, Veracruz. Universidad veracruzana Intercultural (UVI), Sede Totonacapan.

Del Amo Rodríguez, S., Vergara Tenorio, C., Ramos Prado, J. M. (2014). Los valores y responsabilidades en la organización para alcanzar el desarrollo sustentable en forma participativa. Informe de investigación del Cuerpo Académico "Manejo y conservación de recursos bioculturales". UV-Centro de Investigaciones Tropicales.

De LA PEÑA, G. (2004). Los nuevos intermediarios étnicos, el movimiento indígena y la sociedad civil: dos estudios de caso en el occidente mexicano. Xalapa: UV (Cuadernos de la Sociedad Civil, 9).

Durand Ponte, V. M. (2004). Ciudadanía y cultura política. México 1993-2001. México: Siglo XXI.

García García, D. (2016). Nakupolis: Ciudad totonaca del futuro (sueño, realidad o utopía). La Jornada del Campo (109), pp. 37-38. Recuperado de http: / / www.jornada.unam.mx/2016/10/15/cam-ciudad.html

García Marcial, L., Hernández Vázquez, I. E. (2017). Kinkachikikan Coyutla. Trabajo final de la Experiencia Educativa Historia, Territorio e Identidad. Espinal, Veracruz: UVI Totonacapan. 
García Ramos, C. (2016). Universo cultural: nuestra cultura totonaca tradicional. La Jornada del Campo (109) pp. 7-8 Recuperado de http://www.jornada.unam.mx/2016/10/15/cam-universo.html

García Ramos, C., García Flores, A. (2016). Xalichiwin/Lengua, cultura e identidad totonaca. La Jornada del Campo (109), p. 9. Recuperado de http://www.jornada.unam.mx/2016/10/15/cam-totonaca.html

GASCHÉ, J. (2008). La motivación política de la educación intercultural indígena y sus exigencias pedagógicas. ¿Hasta dónde abarca la interculturalidad? En BerTElY, M., Gasché, J., Podestá, R. (Coords.), Educando en la diversidad cultural. Investigaciones y experiencias educativas interculturales y bilingües (pp. 367-397). Quito: Ediciones Abya-Yala, CIESAS, Instituto de Investigaciones de la Amazonía Peruana (IIAP).

Guadarrama Olivera, M. (1987). Ritos y Fiestas. En Urías Hermosillo, M. (Coord.), Coxquihui, Chumatlán y Zozocolco de Hidalgo: Tres municipios totonacos del Estado de Veracruz. (Historia y realidad actual: 1821-1987) (pp. 318-400). Xalapa: Coordinadora Estatal de Veracruz, Instituto Nacional Indigenista. Mimeografiado.

Masferrer Kan, E. (2004). Los Totonacos. México: CDI/PNUD. Pueblos indígenas del México Contemporáneo.

Muñoz Marcos, A., Vicente Hernández, L., Santiago Francisco, M. (2015). Organización y Participación para la Construcción de Ciudadanía, en la Defensa de los Derechos a la Salud con Mujeres de la comunidad de Buena Vista, Espinal, Veracruz. Tesis de Licenciatura en Gestión Intercultural para el Desarrollo. UVI, Sede Totonacapan.

Ramírez Melgarejo, R. (2002). La política del Estado mexicano en los procesos agrícolas y agrarios de los totonacos. Xalapa: UV.

Salazar, L., Woldenberg, J. (2008). Principios y valores de la democracia. México: Instituto Federal Electoral (Cuadernos de Divulgación de la Cultura Democrática, 1).

Segura Sebastián, G. (2008). Las mayordomías en Zozocolco: Arte y tradición indígena totonaca. Veracruz: Instituto Veracruzano de la Cultura (IVEC) (Colección Tierra Fértil).

Urías Hermosillo, M. (1987). Nacer en el Totonacapan. En Urías Hermosillo, M. (Coord.), Coxquihui, Chumatlán y Zozocolco de Hidalgo: Tres municipios totonacos del Estado de Veracruz. (Historia y realidad actual: 1821-1987) (pp. 1-103). Xalapa: 
Instituto Nacional Indigenista-Coordinadora Estatal de Veracruz. Mimeografiado.

Weber, M. (1984). Economía y Sociedad. México: Fondo de Cultura Económica.

ZENNO, M. (2007). El sistema de cargos como mecanismo para mejorar la vida rural en la sociedad urbanizada. En Hernández-Díaz, J. (Coord.), Ciudadanías diferenciadas en un estado multicultural: los usos y costumbres en Oaxaca (pp. 347383). México: Siglo XXI, Universidad Autónoma Benito Juárez de Oaxaca. 